\title{
Epidemic of Non-Communicable Diseases in Jamaica: Monsters Awoken from Lifestyle Practices
}

\author{
Paul Andrew Bourne ${ }^{1}$, Cynthia Francis ${ }^{2}$, Charlene Sharpe-Pryce ${ }^{3}$, Angela Hudson-Davis ${ }^{4}$, \\ Ikhalfani Solan ${ }^{5}$, Olive Watson-Coleman ${ }^{6}$ \\ ${ }^{1}$ Socio-Medical Research Institute, Kingston, Jamaica \\ ${ }^{2}$ University of Technology, Kingston, Jamaica \\ ${ }^{3}$ Department of History, Northern Caribbean University, Mandeville, Jamaica \\ ${ }^{4}$ Capella University, Minneapolis, USA \\ ${ }^{5}$ Department of Mathematics and Computer Science, South Carolina State University, San Diego, USA \\ ${ }^{6}$ Southern Connecticut State University, New Haven, USA \\ Email: "paulbourne1@yahoo.com
}

Received 20 February 2014; revised 21 March 2014; accepted 31 March 2014

Copyright (C) 2014 by authors and OALib.

This work is licensed under the Creative Commons Attribution International License (CC BY). http://creativecommons.org/licenses/by/4.0/

cc) (i) Open Access

\section{Abstract}

Of the 57 million deaths that occurred in the world in 2008, 63 percent were due to chronic noncommunicable diseases (CNCDs), and the majority of those who died were women and elderly people. Objectives: To evaluate health indices of those in the retirement aged cohort and working aged cohort; to determine rates of comorbidity for those in the retirement aged and the working aged cohorts; to compute the prevalence rate of specific chronic non-communicable diseases and to calculate death rates for those in retirement aged and the working aged cohorts. Methods: Jamaica Survey of Living Conditions (JSLC) is a national cross-sectional probability survey that is conducted yearly by two governmental agencies in Jamaica. The current sample is 4313 Jamaicans who are either in the working or retirement aged cohorts from 2007 JSLC survey as well as death statistics from 2002 to 2008 . Findings: In 2007, the prevalence rate of deaths that occur due to CNCDs is $50.7 \%$ (male, $45.2 \%$; female, 59.5\%); $12 \%$ of those in the working aged population indicate having an illness compared to $43.2 \%$ of those in the retirement aged cohort; $23.7 \%$ of retirement aged cohorts reported having diabetes compared to $15 \%$ of those in the working aged cohort, and those in the retirement aged cohort imply having hypertension $\mathbf{1 . 6}$ times more than those in the working aged cohort. The rate of comorbidity is $20.6 \%$ (retirement aged cohort, $27.4 \%$; working aged cohort, $15.6 \%$ ). The prevalence rate of those with CNCDs is $37.6 \%$ for those in the retirement aged cohort and $\mathbf{8 . 2 \%}$ for those in the working aged cohort. Conclusion: It is imperative that age, gender, area of residence specific and culturally relevant policies be developed in order

\footnotetext{
${ }^{*}$ Corresponding author.
}

How to cite this paper: Bourne, P.A., Francis, C., Sharpe-Pryce, C., Hudson-Davis, A., Solan, I. and Watson-Coleman, O. (2014) Epidemic of Non-Communicable Diseases in Jamaica: Monsters Awoken from Lifestyle Practices. Open Access Library Journal, 1: e282. http://dx.doi.org/10.4236/oalib.1100282 
to effectively address these health matters without delay.

\title{
Keywords
}

\author{
Cardiovascular Diseases, Cerebrovascular Diseases, Health Indices, Non-Communicable Diseases, \\ Retirement Aged Cohort, Working Aged Cohort
}

\section{Introduction}

Globally, chronic non-communicable diseases (CNCDs) singly account for the majority of human deaths in spite of mortality to crime and violence. The World Health Organization (WHO) and the United Nations Secretary General, Ban Ki-moon, opine that 3 in every 5 deaths globally are caused by CNCDs [1] [2]. WHO reports that $80 \%$ of CNCDs are in low and middle income countries (the developing world) [1], implying that there is a global public health burden of CNCDs in poor- to middle-income nations [3]. Then there is the postulation by WHO that age-specific mortality rates from chronic non-communicable diseases are greater in sub-Saharan Africa than in established market economies [4]. Like sub-Sahara Africa, the Caribbean region has the highest CNCDs in the Americas and 30 percent of all deaths in the Region of the Americas are due to CNCDs [5], which indicates that there is public health as well as economic burden from CNCDs in Caribbean countries [5] [6]. The overall scenario is not complete without the inclusion of females, older people, health indices and poverty.

It can be deduced from the statistics of the WHO that there is an association between poverty and chronic non-communicable diseases. This is more than a deduction as studies have empirically established the strong statistical correlation between poverty and illness [7] [8]. A question which needs to be asked is who are the poor? From the already established fact, using statistics from the WHO, approximately $60 \%$ of all deaths are caused by CNCDs, and on average of the 35 million annual mortality, 51.4\% are female [1]. The burden from CNCDs is clearly more prevalent in females from developing nations as well as older females. In Cameroon, although, less than $43 \%$ of deaths are due to CNCDs, the matter is still a female as well as old people's phenomenon [9]. Studies have shown that $29 \%$ of CNCDs deaths in the low- to middle-income countries occurred among the working aged population (<60 years) [5] [10]; but globally, it is $44 \%$ before 70 years old [5] and this describes a burden on the working aged population.

Of the ten leading causes of mortality in Jamaica, seven of them are non-communicable conditions such as diabetes, cancers, respiratory conditions, ischaemic heart diseases, hypertension, cerebrovascular and other heart diseases [11]. As in Jamaica, which is evident in the wider Caribbean, the four leading causes of mortality are heart diseases, cancers, stroke and diabetes [12]. Deaths due to chronic non-communicable diseases are high in Jamaica as in other countries [1] such as Cameroon [9], South Africa [13], and United Kingdom [14]. In 2008, the region of the Americas [3] recorded 79\% of all deaths occurring to CNCDs compared to 78\% in low- to middle-income countries, and 22\% in high income nations [3] [5] and in 2006, 65\% of deaths are caused by CNCDs in the Caribbean [12]. According to Hospedales et al., people in the English-speaking Caribbean islands are mostly affected by CNCDs as in the Americas [5], and Wilks et al. [15]; using Jamaicans ages 15 - 74 years, discovered that $45 \%$ of respondents have three primary chronic conditions-diabetes (7.9\%), hypertension (25.2\%) and high cholesterol (11.7). It is also reported that 35.3\% of respondents were in the pre-hypertensive stage; $50.7 \%$ are aware that they have hypertension; $76.1 \%$ know that they have diabetes and $14.0 \%$ are aware that they have high cholesterol, which speaks to the public health challenge in Jamaica like in the wider Caribbean [5] [12] [16] [17]. These reports offer insights into the burdens of lifestyle practices in the Region.

Smith and Menah [18] postulated that CNCDs are owing to ageing, global marketing of tobacco and food, sedentary lifestyles and urbanization. It is well document that CNCDs is a health burden globally, particularly in the Caribbean region. When CNCDs are disaggregated by gender and age, the individual burden is mostly experienced by females and elderly people. In 2010, Ban Ki-moon, United Nations Secretary-General, opines that CNCDs are the biggest threat to women's health worldwide, particularly during their most productive years [2]. The burden on CNCDs extends beyond the individual to the family, community, society, nation and the world because of their healthcare and productivity influence. Hence, a study on the health status of those with CNCDs among the elderly (60+ years) and the working aged cohorts would provide pertinent information for policy makers, researchers, health professionals and other peoples. The justifications for such a study are: understand- 
ing health of two different cohorts, be knowledgeable of the disparities, recognize health matters and how they shift between the two cohorts. In a search of the literature, we did not find a single research that has examined health indices including non-communicable diseases of those in the working age and the retirement age cohorts. Particularly in the English-speaking Caribbean region with the highest prevalence of CNCDs in the Americas; such a study will provide critical information for policy intervention. It follows that any secrecy in a matter of such importance, especially because Jamaica is a member of the Caribbean region, that experiencing such a high prevalence of morbidity and mortality to CNCDs, lessens the gains made in public health and life expectancy since the 1970s. As such, in this research, we seek to evaluate health indices of those in the retirement aged cohort and working aged cohort; to determine rates of comorbidity for those in the retirement aged and the working aged cohorts; to compute the prevalence rate occurring to particular chronic non-communicable diseases and to calculate death rates for those in retirement aged and the working aged cohorts.

\section{Purpose of the Research}

This is a national cross-sectional survey that examines CNCDs in two different cohorts of Jamaicans (i.e., retirement aged and working aged cohorts) as well as mortality and mortality rates for the two cohorts in an effort to guide policy makers in institute measures that are driven by empirical findings.

\section{Materials and Methods}

The Planning Institute of Jamaica and the Statistical Institute of Jamaica are two governmental agencies that conduct annual national probability surveys called the Jamaica Survey of Living Conditions, which seeks to guide policy formulations. The JSLC's cross-sectional descriptive surveys are collected using stratified random sampling techniques. It compiles data on households' characteristics, health, education, expenditure, social programmes, and other information. The survey results are gathered by using a standardized instrument (i.e., questionnaire) that on average takes approximately 45 minutes to complete by each respondent. The JSLC is modeled from the World Bank's Living Standards Measurement Study household survey [19]. There are some modifications to the LSMS, as JSLC is more focused on policy impacts and therefore this is reflected in the collected data.

According to the JSLC [19], the sample is weighted to reflect the population of Jamaica. The households in the JSLC are interviewed on an annual basis for a period of up to four years, after which a new representative sampling frame is redesign and drawn. A detailed presentation of the sampling techniques is in other published works [20] [21]. The data are entered, stored and retrieved in the Statistical Packages for the Social Sciences (SPSS) for Windows, Version 21.0. For this study, descriptive statistics are performed for the socio-demographic characteristics of the sample (percentages); the bivariate analyses are all chi-square analyses (cross tabulations). A p-value $<5 \%$ was chosen to indicate statistical significance (i.e., 95\% confidence interval).

Data on mortality and deaths due to chronic conditions were used to compute prevalence rates. The data are taken from the 2009 Demographic Statistics published by the Statistical Institute of Jamaica [11]. The period for the data ranges from 2002 to 2008; with deaths due to CNCDs from 2006 to 2008.

\section{Definition of Variables}

Health: This is defined as the self-rated health status of an individual.

Good health: Is a binary variable where $1=$ at least good self-rated health status and $0=$ otherwise.

Age: This is the total number of years lived since birth, measured from one birthday to the next.

Retirement aged cohort: This is dependent on the gender of the individual. For females, the retirement age is 60 years and for males it is 65 years in Jamaica. These are used to ascertain those in the retirement aged cohort for this study. Hence, 60+ and 65+ years mark the retirement aged cohort for females and males in Jamaica, respectively.

Working aged cohort: This is determined based on the gender of the individual. In Jamaica, the working age for females is 18 to 60 years and for males, it is 18 to 65 years. Based on the legal regulations in Jamaica, the present study applies this to arrive with the working aged cohort (males, 18 - 65 years old; females, 18 - 60 years old).

Health-care Seeking Behavior (or visits to medical professional): This is derived from the question "Have 
you sought medical attention in the last four weeks (using the survey period), where $1=$ yes and $0=$ otherwise.

Other NCDs: These include malignant neoplasm, ischaemic and other heart diseases, and high cholesterol.

Health Insurance Coverage: This is a binary measure, in which 1 denotes self-reported ownership of private and/or public health insurance coverage and 0 is otherwise.

Purchased prescribed medications: This is an individual reporting that he/she filled the prescription that he/she received on visit to the health care practitioner(s).

Health indices: For this paper, this concept is measured using illness (or self-reported illness), health-care seeking behavior (or health care utilization), health insurance coverage, and health insurance utilization.

\section{Abbreviations and Acronyms}

NCDs: Noncommunicable diseases

CNCDs: Chronic noncommunicable diseases

LSMS: Living Standards Measurement Study

JSLC: Jamaica Survey of Living Conditions

\section{Results and Analysis of Findings}

\section{Tables}

Using data from the Statistical Institute [11], we calculate deaths from CNCDs, elderly (ages 60+ years old) and for the period 2002-2008, which show that between $47 \%$ - 51\% (male, $43 \%-46 \%$; female, $55 \%-60 \%$ ) of deaths occur due to CNCDs and at least 55\% of total mortality (as high at 65\%) are among those 60+ years old (male, 54\% - 60\%; female, 68\% - 72\%), as illustrated in Table 1 .

Table 1. Deaths and death rates of 60+ year old population, 2002-2008.

\begin{tabular}{|c|c|c|c|c|c|c|c|}
\hline \multirow{2}{*}{ Age } & \multicolumn{7}{|c|}{ Male } \\
\hline & 2008 & 2007 & 2006 & 2005 & 2004 & 2003 & 2002 \\
\hline $60-64$ & 514 & 529 & 531 & 567 & 573 & 539 & 558 \\
\hline $65-69$ & 727 & 630 & 616 & 658 & 651 & 685 & 703 \\
\hline $70-74$ & 844 & 816 & 913 & 975 & 934 & 862 & 642 \\
\hline $75^{+}$ & 3242 & 3052 & 3163 & 3379 & 3158 & 3267 & 3186 \\
\hline Males, 60+ deaths & 5327 & 5027 & 5223 & 5579 & 5316 & 5353 & 5089 \\
\hline \multirow[t]{2}{*}{ Total males deaths } & 9581 & 9137 & 8917 & 9473 & 9210 & 9045 & 9234 \\
\hline & \multicolumn{7}{|c|}{ Females } \\
\hline \multicolumn{8}{|l|}{ Age } \\
\hline $60-64$ & 349 & 386 & 384 & 415 & 403 & 415 & 406 \\
\hline $65-69$ & 439 & 546 & 463 & 501 & 543 & 497 & 539 \\
\hline $70-74$ & 622 & 678 & 671 & 727 & 690 & 701 & 764 \\
\hline $75+$ & 3716 & 3931 & 3750 & 4061 & 3753 & 3749 & 3595 \\
\hline Females, $60+$ deaths & 5126 & 5541 & 5268 & 5704 & 5389 & 5362 & 5304 \\
\hline Total females deaths & 7419 & 7911 & 7400 & 8079 & 7695 & 7654 & 7784 \\
\hline Total $60+$ deaths & 10453 & 10568 & 10491 & 11283 & 10705 & 10715 & 10393 \\
\hline Population deaths & 17000 & 17048 & 16317 & 17552 & 19906 & 16702 & 17018 \\
\hline $60+$ death rate (per 100 deaths) & 61.49 & 61.99 & 64.29 & 64.28 & 53.78 & 64.15 & 61.07 \\
\hline 60+ Male death (per 100 deaths) & 55.60 & 55.02 & 58.57 & 58.89 & 57.72 & 59.18 & 55.11 \\
\hline 60+ Female death (per 100 deaths) & 69.09 & 70.04 & 71.19 & 70.60 & 70.03 & 70.05 & 68.14 \\
\hline
\end{tabular}

${ }^{\mathrm{a} C}$ Computed by Paul Andrew Bourne from the 2010 Demographic Statistics by the Statistical Institute of Jamaica. 
Table 2 shows deaths and death rates of males and females in the working aged population for 2002-to-2008. Yearly, between 29 and 34 percent of those in the working aged population die and this is greater for males than females.

Table 3 represents information on deaths due to CNCDs of males and females for 2006-2008, and the prevalence rate of deaths because of CNCDs for each of the studied year disaggregated by gender. In 2006, the prevalence rate of deaths due to CNCDs is 50.1\% with a marginal increase in 2007 (to 50.7\%) and slight decrease

Table 2. Deaths and death rates of males and females 15 - 64 years old, 2002-2008).

\begin{tabular}{|c|c|c|c|c|c|c|c|}
\hline \multirow{2}{*}{ Age } & \multicolumn{7}{|c|}{ Male } \\
\hline & 2008 & 2007 & 2006 & 2005 & 2004 & 2003 & 2002 \\
\hline \multicolumn{8}{|l|}{ Age } \\
\hline $15-19$ & 219 & 181 & 182 & 195 & 171 & 158 & 176 \\
\hline $20-24$ & 485 & 393 & 378 & 405 & 365 & 285 & 333 \\
\hline $25-29$ & 465 & 455 & 373 & 398 & 377 & 356 & 383 \\
\hline $30-34$ & 398 & 375 & 363 & 387 & 408 & 345 & 408 \\
\hline $35-39$ & 395 & 393 & 328 & 351 & 389 & 343 & 381 \\
\hline $40-44$ & 327 & 352 & 347 & 371 & 365 & 313 & 329 \\
\hline $45-49$ & 366 & 366 & 309 & 330 & 335 & 363 & 305 \\
\hline $50-54$ & 401 & 375 & 359 & 383 & 360 & 344 & 333 \\
\hline $55-59$ & 435 & 427 & 372 & 397 & 413 & 436 & 453 \\
\hline $60-64$ & 514 & 529 & 531 & 567 & 573 & 539 & 558 \\
\hline Death of males, ages 15 - 64 years old & 4005 & 3846 & 3542 & 3784 & 3756 & 3482 & 3659 \\
\hline \multirow[t]{2}{*}{ Total male deaths } & 9581 & 9137 & 8917 & 9473 & 9210 & 9045 & 9234 \\
\hline & \multicolumn{7}{|c|}{ Females } \\
\hline Age & 2008 & 2007 & 2006 & 2005 & 2004 & 2003 & 2002 \\
\hline $15-19$ & 72 & 65 & 49 & 53 & 65 & 55 & 86 \\
\hline $20-24$ & 97 & 106 & 94 & 101 & 98 & 92 & 113 \\
\hline $25-29$ & 125 & 114 & 140 & 152 & 136 & 135 & 171 \\
\hline $30-34$ & 129 & 167 & 157 & 169 & 143 & 172 & 173 \\
\hline $35-39$ & 162 & 178 & 202 & 218 & 198 & 192 & 200 \\
\hline $40-44$ & 253 & 250 & 209 & 227 & 248 & 249 & 232 \\
\hline $45-49$ & 269 & 264 & 247 & 268 & 262 & 210 & 234 \\
\hline $50-54$ & 302 & 322 & 234 & 254 & 255 & 278 & 266 \\
\hline $55-59$ & 322 & 312 & 252 & 273 & 272 & 286 & 317 \\
\hline Death of females, ages 15 - 64 years old & 1659 & 1778 & 1584 & 1715 & 1677 & 1669 & 1792 \\
\hline Total females deaths & 7419 & 7911 & 7400 & 8079 & 7695 & 7654 & 7784 \\
\hline Total deaths, working aged population & 5664 & 5624 & 5126 & 5499 & 5433 & 5151 & 5451 \\
\hline Population deaths & 17000 & 17048 & 16317 & 17552 & 19906 & 16702 & 17018 \\
\hline${ }^{1}$ Death rate for working population (in \%) & 33.32 & 32.99 & 31.42 & 31.33 & 27.29 & 30.84 & 32.03 \\
\hline${ }^{2}$ Death rate, Male working population (in \%) & 41.80 & 42.09 & 39.72 & 39.95 & 40.78 & 38.50 & 39.63 \\
\hline${ }^{3}$ Death rate, Female working population (in \%) & 22.36 & 22.48 & 21.41 & 21.23 & 21.79 & 21.81 & 23.02 \\
\hline
\end{tabular}

\footnotetext{
${ }^{1-3}$ Computed by Paul Andrew Bourne from the 2010 Demographic Statistics by the Statistical Institute of Jamaica.
} 
Table 3. Deaths and death rates of males and females 15 - 64 years old, 2002-2008).

\begin{tabular}{|c|c|c|c|c|c|c|c|c|c|c|c|c|}
\hline \multirow{3}{*}{ Condition } & \multicolumn{12}{|c|}{ Cause of death } \\
\hline & \multicolumn{4}{|c|}{2008} & \multicolumn{4}{|c|}{2007} & \multicolumn{4}{|c|}{2006} \\
\hline & Male & Female & Total & $C S P R^{1}$ & Male & Female & Total & $C S P R^{1}$ & Male & Female & Total & $C S P R^{1}$ \\
\hline Cerebrovascular & 873 & 1135 & 2008 & 12.27 & 878 & 1131 & 2009 & 12.09 & 772 & 969 & 1741 & 11.36 \\
\hline Diabetes & 630 & 1079 & 1709 & 10.44 & 671 & 1017 & 1688 & 10.16 & 633 & 1063 & 1696 & 11.07 \\
\hline Ischaemic Heart & 476 & 500 & 976 & 5.96 & 543 & 549 & 1092 & 6.57 & 511 & 521 & 1032 & 6.74 \\
\hline Hypertension & 449 & 588 & 1037 & 6.33 & 436 & 631 & 1067 & 6.42 & 393 & 514 & 907 & 5.92 \\
\hline Chronic Respiratory & 337 & & 337 & 2.06 & 336 & & 336 & 2.02 & 310 & & 310 & 2.02 \\
\hline Other Heart Diseases & 332 & 347 & 679 & 4.15 & 352 & 363 & 715 & 4.30 & 335 & 309 & 644 & 4.20 \\
\hline Cancers & 876 & 551 & 1427 & 8.72 & 941 & 581 & 1522 & 9.16 & 857 & 491 & 1348 & 8.80 \\
\hline Total deaths to CNCDs & 3973 & 4200 & 8173 & 49.92 & 4157 & 4272 & 8429 & 50.73 & 3811 & 3867 & 7678 & 50.11 \\
\hline Population, deaths & 8945 & 7362 & 16371 & & 9188 & 7180 & 16614 & & 8479 & 6841 & 15321 & \\
\hline Prevalence rate & 44.4 & 57.1 & 49.9 & & 45.2 & 59.5 & 50.7 & & 45.0 & 56.5 & 50.1 & \\
\hline
\end{tabular}

${ }^{1-3}$ Computed by Paul Andrew Bourne from the 2010 Demographic Statistics by the Statistical Institute of Jamaica.

to $49.9 \%$ in 2008, which denotes that at least 50\% of deaths in Jamaica for 2006-2008 are a result of CNCDs. On examination of Table 3, the majority of deaths because of CNCDs are owing to cerebrovascular diseases followed by diabetes and cancers. There are specific causes of deaths due to CNCDs that are greater among females than for males such as cerebrovascular diseases, diabetes, and hypertension; while malignant neoplasm is substantially a male condition.

Table 4 shows the socio-demographic characteristics of the sampled population. The percentage of those below the poverty line (income quintile $=1$ ) is greater among the retirement aged cohort (20.7) than for those in the working aged cohort (15.9); disparity was also observed in the marital status categorization; social assistance; head of household, and gender of respondents.

Table 5 details information on health indices for the sampled populations. Among those in the working aged cohort, at least good health status is $84.4 \%$ compare to $38.4 \%$ for those in the retirement aged cohort. Four times more of those in the retirement aged cohort reports having an illness compare to those in the working aged cohort. Five percent more people in the retirement aged cohort sought medical care than those in the working aged cohort. The prevalence rate of CNCDs among those in the working aged cohort is 8.2\% (i.e., 295/3598 × 100) compared to $37.6 \%$ for those in the retirement aged cohort $(269 / 715 \times 100)$. Two times the number of people in the retirement aged cohort has diabetes compared to those in the working aged cohort, which is the same for those with hypertension and arthritis.

Table 6 presents comorbidity of the sampled populations. Among the retirement aged cohort, $68.7 \%$ of those with diabetes report having hypertension which is $14.3 \%$ for those in the working aged cohort. Sixty-four and three tenths percent of the hypertensive in the retirement age cohort report having diabetes compared to $25 \%$ of those in the working aged cohort. Statistical correlations emerged between comorbidity $(P<0.05)$. A computation can be made here of the prevalence rate of comorbidity in each cohort categorization as well as overall for this study. The comorbidity rate for the studied sample is $20.6 \%(147 / 712 \times 100)$, which is $27.4 \%$ for the retirement aged cohort $(83 / 303 \times 100)$ and $15.6 \%$ for those in the working aged cohort $(64 / 409 \times 100)$.

Table 7 presents cross tabulation results of chronic condition and gender as well as chronic conditions and area of residence. More females have diabetes (20.2\%) than males (14.7\%) in the retirement aged cohort, which is also the same for those with hypertension (males, 23.4\%; females, 34.8\%) and arthritis (males, $6.3 \%$; females, $7.6 \%)$. However, more males report having other chronic conditions $(55.8 \%)$ compared to females $(37.4 \%), \chi^{2}=$ 12.192, $\mathrm{P}=0.007$. Females are more likely to report having diabetes (29.9\%) than males (18.5\%) for those in the working aged cohort as well as being hypertensive (males, 39.1\%; females, $47.5 \%$ ), which is similarly the case among those in the retirement aged cohort. However, the difference occurred between the genders with 
Table 4. Health indices of the sampled population, $n=4313$.

\begin{tabular}{|c|c|c|c|c|}
\hline \multirow{2}{*}{ Characteristic } & \multicolumn{2}{|c|}{$\begin{array}{l}\text { Retired population } \\
\quad \mathrm{N}=715\end{array}$} & \multicolumn{2}{|c|}{$\begin{array}{l}\text { Working aged population } \\
\qquad \mathrm{N}=3598\end{array}$} \\
\hline & $\mathrm{N}$ & $\%$ & $\mathrm{~N}$ & $\%$ \\
\hline \multicolumn{5}{|l|}{ Sex } \\
\hline Males & 276 & 38.9 & 1774 & 49.3 \\
\hline Females & 439 & 61.4 & 1824 & 50.7 \\
\hline \multicolumn{5}{|l|}{ Marital Status } \\
\hline Married & 263 & 37.6 & 815 & 23.3 \\
\hline Single & 207 & 29.6 & 2562 & 73.2 \\
\hline Divorced & 24 & 3.4 & 54 & 1.5 \\
\hline Separated & 12 & 1.7 & 28 & 0.8 \\
\hline Widowed & 193 & 27.6 & 39 & 1.2 \\
\hline \multicolumn{5}{|l|}{ Social Assistance } \\
\hline Yes & 115 & 16.4 & 43 & 1.2 \\
\hline No & 588 & 83.6 & 3461 & 98.8 \\
\hline \multicolumn{5}{|l|}{ Head of household } \\
\hline No & 238 & 33.3 & 2047 & 56.9 \\
\hline Yes & 477 & 66.7 & 1551 & 43.1 \\
\hline \multicolumn{5}{|l|}{ Income Quintile } \\
\hline 1 & 148 & 20.7 & 572 & 15.9 \\
\hline 2 & 126 & 17.6 & 661 & 18.4 \\
\hline 3 & 154 & 21.5 & 706 & 19.6 \\
\hline 4 & 132 & 18.5 & 755 & 21.0 \\
\hline 5 & 155 & 21.7 & 904 & 25.1 \\
\hline \multicolumn{5}{|l|}{ Area of residence } \\
\hline Urban & 202 & 28.3 & 1129 & 31.4 \\
\hline Peri Urban & 151 & 21.1 & 811 & 22.5 \\
\hline Rural & 362 & 50.6 & 1658 & 46.1 \\
\hline
\end{tabular}

arthritis for the two cohorts. For those in the working aged cohort, more males are shown to have arthritis (19.6\%) than females (9.6\%), which is a reverse among those in the retirement aged cohort. Rural residents are more likely to have diabetes than those who dwell in other areas, while peri-urban dwellers are more likely to have hypertension and urban residents are more likely to have others chronic conditions as well as arthritis among those in the retirement aged cohort. This is different for those in the working aged population as urban residents are more likely to have diabetes, rural dwellers to have hypertension and arthritis and urban residents to have other chronic conditions.

Table 8 shows a cross tabulation between chronic conditions and gender for two aged cohorts (retirement and working). In each cohort, there is a feminization of chronic non-communicable diseases. Sixty-eight and four tenths percent of those with chronic conditions are females and 31.6 percent males of those in the retirement aged cohort compared to 74.7 percent females and 25.3 percent males of those in the working aged cohort.

\section{Discussion}

It is well established in the literature that chronic non-communicable diseases (CNCDs) are the leading cause of 
Table 5. Health indices of the sampled population, $n=4313$.

\begin{tabular}{|c|c|c|c|c|}
\hline \multirow{2}{*}{ Characteristic } & \multicolumn{2}{|c|}{$\begin{array}{l}\text { Retired Population } \\
\qquad \mathrm{N}=715\end{array}$} & \multicolumn{2}{|c|}{$\begin{array}{c}\text { Working aged } \\
\text { population } \mathrm{N}=3598\end{array}$} \\
\hline & $\mathrm{N}$ & $\%$ & $\mathrm{~N}$ & $\%$ \\
\hline \multicolumn{5}{|l|}{ Self-reported Illness } \\
\hline Yes & 303 & 43.2 & 409 & 11.7 \\
\hline No & 399 & 56.8 & 309 & 88.3 \\
\hline \multicolumn{5}{|l|}{ Typology of Conditions } \\
\hline \multicolumn{5}{|l|}{ Communicable } \\
\hline Influenza, diarrhoea, etc & 27 & 9.1 & 76 & 20.5 \\
\hline \multicolumn{5}{|l|}{ Chronic non-communicable } \\
\hline Diabetes & 70 & 23.7 & 54 & 14.5 \\
\hline Hypertension & 120 & 40.5 & 91 & 24.9 \\
\hline Arthritis & 35 & 11.8 & 21 & 5.7 \\
\hline Other & 44 & 14.9 & 129 & 34.4 \\
\hline \multicolumn{5}{|l|}{ Health-Care Seeking Behavior } \\
\hline Yes & 219 & 71.3 & 282 & 66.5 \\
\hline No & 88 & 28.7 & 142 & 33.5 \\
\hline \multicolumn{5}{|l|}{ Self-reported Health } \\
\hline Very good & 61 & 8.7 & 1288 & 37.0 \\
\hline Good & 209 & 29.7 & 1651 & 47.4 \\
\hline Fair & 278 & 39.5 & 423 & 12.1 \\
\hline Poor & 125 & 17.8 & 106 & 3.0 \\
\hline Very poor & 30 & 4.3 & 16 & 0.5 \\
\hline \multicolumn{5}{|l|}{ Health Facility Utilization } \\
\hline Private & 86 & 78.8 & 125 & 85.6 \\
\hline Public & 23 & 21.1 & 21 & 14.4 \\
\hline \multicolumn{5}{|l|}{ Health Insurance Coverage } \\
\hline No & 492 & 70.7 & 2710 & 78.3 \\
\hline Yes & 204 & 29.3 & 751 & 21.7 \\
\hline \multicolumn{5}{|l|}{ Purchased Medications by } \\
\hline Attended Private Facility & 197 & 80.8 & 253 & 83.0 \\
\hline Attended Public Facility & 303 & 43.2 & 409 & 11.7 \\
\hline
\end{tabular}

mortality in the world. The World Health Organization (WHO) found that $60 \%$ of global deaths are caused by CNCDs and that $80 \%$ of these deaths occurred in low-to middle-income countries [1]. Generally, these human deaths are due to CNCDs and are greater among females and aged people [1] [2], indicating the feminization of CNCDs and the high prevalence of mortality among elderly people because of CNCDs. According to Hospedales et al. [5], in 2008, 63 in every 100 deaths in the world are due to CNCDs and that 44\% occurred before 70 years. For the same year, the current findings revealed that $50 \%$ of total deaths in Jamaica was due to CNCDs (males, 44\%; females, 57\%) and that $62 \%$ of all deaths in Jamaica can be ascribed to people 60+ years old (males, 56\%; females, 69\%). This study concurs with the literature that deaths are mostly due to CNCDs, particularly among elderly people and females. It can be concluded, therefore, that a small percent of human deaths, 
Table 6. Comorbidity for the sampled population (retirement and working aged cohorts), $\mathrm{n}=147$.

\begin{tabular}{|c|c|c|c|c|}
\hline \multirow{2}{*}{ Characteristic } & \multicolumn{4}{|c|}{ Typology } \\
\hline & Diabetes N (\%) & Hypertension N (\%) & Arthritis N (\%) & Other N (\%) \\
\hline \multicolumn{5}{|c|}{ Retirement aged Cohort $^{1}$} \\
\hline Diabetes & - & 27 (64.3) & $0(0.0)$ & $1(50.0)$ \\
\hline Hypertension & $22(68.7)$ & - & $4(66.7)$ & $0(0.0)$ \\
\hline Arthritis & $4(12.5)$ & $5(11.9)$ & - & $1(50.0)$ \\
\hline Other & $6(18.8)$ & $10(23.8)$ & $2(33.3)$ & - \\
\hline \multicolumn{5}{|c|}{ Working aged Cohort ${ }^{2}$} \\
\hline Diabetes & - & $1(25.0)$ & $1(33.3)$ & $4(13.8)$ \\
\hline Hypertension & $1(14.3)$ & - & $1(33.3)$ & $3(10.3)$ \\
\hline Arthritis & $1(14.3)$ & $1(25.0)$ & - & $22(75.9)$ \\
\hline Other & $5(71.4)$ & $2(50.0)$ & $1(33.4)$ & - \\
\hline
\end{tabular}

${ }^{1} \chi^{2}=89.910, \mathrm{P}<0.0001 ;{ }^{2} \chi^{2}=51.282, \mathrm{P}=0.001$

Table 7. Cross tabulation of chronic conditions and gender as well as area of residence.

\begin{tabular}{|c|c|c|c|c|c|}
\hline \multirow{3}{*}{ Characteristic } & \multicolumn{5}{|c|}{ Typology } \\
\hline & \multicolumn{2}{|c|}{ Gender $^{\mathrm{a}, \mathrm{b}}$} & \multicolumn{3}{|c|}{ Area of residence $\mathrm{e}^{\mathrm{c}, \mathrm{d}}$} \\
\hline & Male & Female & Urban & Peri Urban & Rural \\
\hline \multicolumn{6}{|c|}{ Retirement aged Cohort $^{1}$} \\
\hline Diabetes & $14(14.7)$ & $40(20.2)$ & $24(33.8)$ & $11(20.4)$ & 35 (22.3) \\
\hline Hypertension & $22(23.4)$ & $69(34.8)$ & $24(33.8)$ & $22(40.7)$ & $44(28.0)$ \\
\hline Arthritis & $6(6.3)$ & $15(7.6)$ & $8(11.3)$ & $5(9.3)$ & $8(5.1)$ \\
\hline Other & $53(55.8)$ & $74(37.4)$ & $15(21.1)$ & $16(29.6)$ & $70(44.6)$ \\
\hline \multicolumn{6}{|c|}{ Working aged Cohort ${ }^{2}$} \\
\hline Diabetes & 17 (18.5) & $53(29.9)$ & $8(9.8)$ & $16(30.8)$ & 30 (20.5) \\
\hline Hypertension & $36(39.1)$ & $84(47.5)$ & $25(30.5)$ & $22(42.3)$ & $74(50.7)$ \\
\hline Arthritis & 18 (19.6) & $17(9.6)$ & $8(9.8)$ & $5(9.6)$ & $22(15.1)$ \\
\hline Other & $21(22.8)$ & $23(13.0)$ & $41(50.0)$ & $9(17.3)$ & $20(13.7)$ \\
\hline
\end{tabular}

Note: ${ }^{\mathrm{a}}$ Denotes the cross tabulation between gender and chronic conditions for those in the retirement aged cohort- $\chi^{2}=12.192, \mathrm{P}=0.007 ;{ }^{\mathrm{b}}$ Denotes the cross tabulation between gender and chronic conditions for those in the working aged cohort- $\chi^{2}=9.031, \mathrm{P}=0.029$; ${ }^{\mathrm{C}}$ Denotes the cross tabulation between area of residence and chronic conditions for those in the retirement aged cohort- $\chi^{2}=9.661, \mathrm{P}=0.040$; ${ }^{\mathrm{d}}$ Denotes the cross tabulation between area of residence and chronic conditions for those in the working aged cohort- $\chi^{2}=12.847, \mathrm{P}=0.046$.

Table 8. Cross tabulation of chronic conditions and gender as well as area of residence.

\begin{tabular}{|c|c|c|c|c|}
\hline \multirow{5}{*}{ Characteristic } & \multicolumn{4}{|c|}{ Typology } \\
\hline & \multicolumn{2}{|c|}{ Retirement Aged Cohort ${ }^{\mathrm{a}}$} & \multicolumn{2}{|c|}{ Working Aged Cohort $^{\mathrm{b}}$} \\
\hline & \multicolumn{2}{|c|}{ Chronic Conditions } & \multicolumn{2}{|c|}{ Chronic Conditions } \\
\hline & No & Yes & No & Yes \\
\hline & \multicolumn{2}{|c|}{ No (\%) } & \multicolumn{2}{|c|}{ No (\%) } \\
\hline \multicolumn{5}{|l|}{ Gender } \\
\hline Male & $36(50.7)$ & $7(31.6)$ & $88(43.3)$ & $42(25.3)$ \\
\hline Female & 35 (49.3) & $154(68.4)$ & $115(56.7)$ & $124(74.7)$ \\
\hline
\end{tabular}

Note: ${ }^{\mathrm{a}} \chi^{2}=8.574, \mathrm{P}=0.003 ;{ }^{\mathrm{b}} \chi^{2}=13.037, \mathrm{P}<0.0001$. 
due to CNCDs, happened before 60 years, and that lifestyle practices largely accounted for the high prevalence of deaths among those $60+$ years old.

Smith and Menah [18] attribute deaths, because of CNCDs, to urbanization, sedentary lifestyle, global marketing of tobacco and food, and population aging. Shao [22] opines that $16 \%$ of global deaths results from CNCDS, occurred before 60 years and that $42 \%$ of deaths, due to CNCDS, occurred in low-to middle-income countries and this emphasizes the age disparity in those conditions, which is also the case in Jamaica. Using the perspective that CNCDs are owing to lifestyle practices including physical activity (or the lack of), tobacco and food consumption, the finding of the present study's about the disparity in CNCDs between the age cohorts can be explained by the lifestyle practices of Jamaicans. Wilks et al. [15] find that $74.5 \%$ of Jamaicans ages 15 - 74 years use alcohol (15 - 24 years, 77.5\%; 25 - 34 years, 83.2\%; 35 - 44 years, 80.0\%; 45 - 54 years, 64.0\%; 55 64 years, $65.9 \%$; 65 - 74 years, $48.0 \%$ ); $14.5 \%$ currently smoke cigarette (15 - 24 years, $10.3 \%$; 25 - 34 years, 15.22\%; 35 - 44 years, 13.6\%; 45 - 54 years, 20.7\%; 55 - 64 years, 15.2\%; 65 - 74-years, $17.0 \%)$, 30.0\% are physically inactive (male, $16.0 \%$; female, 43.0 ), and $51.7 \%$ are either overweight or obese. Furthermore among those overweight and obese, $25.3 \%$ and $31.5 \%$ are physically inactively, respectively [15]. Based on aforementioned issues, we have explanations for the prevalence of CNCDs in the present study as early lifestyle practices is resulting in incidence and prevalence of chronic conditions in the working aged and retired aged cohorts.

The present study shows that mortality in Jamaica for the periods 2002-2008 is mostly among people 60+ years old (between 52\% - 65\%), especially females (males, 54\% - 60\%; females, 67\% - 72\%) and that CNCDs account for between $44 \%$ and 52\% for 2006-2008. Using data for 2008 for Jamaica, we can compute the probability of deaths due to CNCDs for the elderly. The probability of deaths caused by CNCDs for those 60+ years old is $0.307 \%$ or $30.7 \%(0.499 \times 0.615)$, which is relatively close to the percentage of those $60+$ years old who died because of CNCDs (42\%) in low-to middle income countries [22]. With the absence of data on causes of deaths disaggregated by age this research is unable to compare for Jamaica against the Americas. However, Hospedales, et al. [5] offer some general information on age cohort of those dying from CNCDs in the Americas, which can be extrapolated for Jamaica. They opine that 30 in every 100 deaths in the Americas are caused by CNCDs before the age of 70 years and 29 in every 100 deaths due to CNCDs are among those in the working aged cohort ( $<60$ years). The deaths statistics of the current research as well as those forwarded by Hospedales, et al. [5] supports the ageing and female phenomena of non-communicable conditions. While these statistics provide information on the general profile of those with CNCDs and mortality statistics, there are many gaps herein that are clarified by this study.

In this study, the prevalence rate of having CNCDs among those in the retirement aged cohort is $37.6 \%$, which is 4.6 times more than that for those in the working aged cohort. Other disparities in CNCDs also appear as it relates to prevalence of comorbidity between the two aforementioned groups of people. The prevalence of comorbidity is $27.4 \%$ for those in the retirement aged cohorts compared to $15.6 \%$ for those in the working aged cohort. Embedded in these findings is the substantial rise in CNCDs after 60+ years, which concurs with the literature [5] [22]. Unlike the literature, this research provides more information on health indices between the two cohorts. This research reveals that $43.2 \%$ of those in the retirement aged cohort report having an illness compared to $11.7 \%$ of those in the working aged cohort. The disparity continues as $23.6 \%$ of those in the retirement aged cohort report having diabetes compared to $14.6 \%$ of those in the working aged cohort, the disparity was even wider for hypertension, $40.5 \%$ and $24.7 \%$ for those in the retirement and working aged cohorts, respectively. The poor health status of elderly cohort is captured in the aforementioned information and reinforced by self-reported health status findings. Eighty-four out of every 100 of those in the working aged cohort indicated having at least good health compared to $38 / 100$ of those in the retirement aged cohort. Bourne and Charles [22] provide understanding of those with hypertension that can be used to extrapolate other non-communicable conditions. They discovered that those with hypertension report a lower health status than those with hypertension and that hypertension is greater among females than males. We can extract from Bourne and Charles' work [22] that having a chronic non-communicable condition decreases an individual health status compared to those without. This is supported by the present study as the overall quality of life of the elderly is lower than those in the working aged cohort ( $<60$ years) and this must be taken within the context that CNCDs is an elderly phenomenon.

Poor health status significantly increases after 60 years and so do CNCDs. It should come as no surprise that there is a wide disparity in prevalence rate in CNCDs between those in the retirement and working aged cohorts. Smith and Menah [18] offers explanation for the rise in CNCDs as attributing to rapid urbanization, sedentary 
lifestyles, global marketing of tobacco and food, and population aging [18], which is equally expressed by other scholars and/or agencies [4] [9] [23]-[26]. We can deduce from Smith and Menah's work that poor lifestyle practices before $60+$ become problematic in the latter years of life, and that these can provide an explanation for health disparities (health status, illness, chronic non-communicable diseases) in the current study between the two cohorts. Among Smith and Menah's [18] rationale for the increase in CNCDs is population ageing or biological ageing. Studies have shown that there is a health transition that occur with ageing at older ages (60+ years) [27] [28] as the human cell degenerate toward death [29] [30]. This, therefore, offers an explanation for increased mortality at 60+ years and CNCDs that afflict the human body at older ages.

According to Gavriolov and Gavrilova [29] [30], using Gompertz's law, there is fundamental quantitative theory of ageing and mortality of certain species (the examples here are as follows-humans, human lice, rats, fruit flies, and flour beetles). Gompertz's law went further to establish that human mortality increase two-fold with every 8 years of an adult life, which means that ageing increases in geometric progression. This phenomenon means that human mortality increases with age of the human adult, but that this becomes less progressive in advanced ages. Thus, biological ageing is a process where the human cells degenerate with years (i.e., the cells die with increasing in age), which is explored in evolutionary biology [31]-[33]. This explains the substantial health disparity in self-reported illnesses between those in the retirement and working aged cohort of the present work. Bogues's perspective offers even more information on the ageing process, when he claims that functionality declines even greater at different stages of the ageing process as well as the increase in health conditions [28].

In Jamaica about 50\% of all deaths are caused by CNCDs which is more than that in Cameroon (43\%) [9], while this is significantly less than the figure for the Americas (79\%) [25] and the world (63\%) [3], these are a burden to the society. The positive of the overall prevalence is somewhat reduced when CNCDs are disaggregated into typology of conditions. In 2008, the WHO discovered that $4 \%$ of total human deaths in the world are caused by diabetes. On the other hand, based on the present study, in Jamaica, the total human deaths that are caused by diabetes is $10.4 \%$. This is similar to the figure reported for the Eastern Caribbean, $10.0 \%$ [16]. While this research reveals that only $6.6 \%$ of total deaths in Jamaica are caused by hypertension, it is substantially higher than the $16.6 \%$ in the Eastern Caribbean countries [16]. Even though the present study finds that it is only 38 out every 100 of those in the retirement aged cohort have a CNCDs and 8/100 of those in the working aged cohort, this disparity, is a cause for concern as there is no denial that poor early lifestyle practices and inactivity before 60 years is significantly eroding the quality of life of those 60+ years old. Hence, what of multi chronic conditions?

This takes the discussion to the issue of comorbidity. In South Africa, the prevalence of comorbidity ( $\geq 2$ chronic conditions) is $22.5 \%$ [13] compared to $20.6 \%$ in the current study. Unlike the study in South Africa [13], in this work it is disaggregated by two cohorts (retirement and working aged). The prevalence rate of comorbidity in Jamaica among those in the retirement aged cohort is $27.4 \%$, which is 1.8 times more than that for those in the working aged cohort. The reality is, those in the retirement aged cohort are more likely to have multimorbidity compared to those in the working aged cohort, and that comorbidity between the two cohorts is also different. Sixty-eight and seven tenths percent of diabetics in the retirement aged cohort have hypertension and this is $14.3 \%$ for those in the working aged cohort. Among the hypertension that are in the retirement aged cohort, $64.3 \%$ of them have diabetes, while it is $25 \%$ for those in the working aged cohort and there was a disparity in the arthritic patients (retirement aged cohort, 66.7\%; working aged cohort, 33.3\%). These disparities in comorbidity in chronic conditions between the two cohorts are indications of epidemiological transition in CNCDs as people before age, especially 60+ years old. Like the Population Reference Bureau indicates that unhealthy lifestyle practices, physical inactivity, tobacco and excessive alcohol consumption account for most of the cases of CNCDs [34], we can further argue that those issues before 60 years later affect the individual post 60 years. Simply put, the high risk factors $<60$ years explain the greater prevalence of morbidity, especially CNCDs, among those 60+ years, women and this increases with more exposure to many the risk factors.

With the English-speaking Caribbean being the most affected by CNCDs [5] and the current findings indicating that there is wide gap between these conditions including comorbidity, the issue as to why must be examined. Puska provides an explanation of epidemic of CNCDs in the Caribbean regions, including Jamaica, aptly this way that "It can only be speculated, why Western countries so far have neglected NCDs in their international health work. It is certainly partly due to inertia in change and to wrong myths and lack of knowledge of the true situation" [35], which cannot be downplayed and/or overlooked in a health discourse on CNCDs in the Carib- 
bean region. Hunter and Reddy [36] outlined that addressing the prevalence of CNCDs must be addressed by the government, clinicians and the health care system. They charged that the government should implement "Antitobacco policy; policies that promote reduction in salt intake; regulation and labeling of processed foods and high-sugar beverages; planning for safe, healthy environments that promote physical activity and limit the transition to a sedentary lifestyle; policies designed to mitigate the harmful effects of alcoholic beverages” [36]. The lack of robust policies to address these public health issue result in the Caribbean region, particularly Jamaica lagging behind other countries. In fact, it was in 2013 that Jamaica introduced a national anti-tobacco policy; however, those matters that are forwarded by Hunter and Reddy have not yet been implemented, fashioned and framed in an effort to address the epidemic of CNCDs.

Policies to address CNCDs, especially in developing nations with the greater prevalence of CNCDs, must target females as they, generally, are more affected by chronic conditions than males [2], which is equally the same in Jamaica, South Africa [37] and the rest of the world [1]-[3]. In this study, at least 68 percent of males and females suffer from chronic non-communicable diseases whether they are in the retirement or working aged cohort. This further justifies the rationale for higher prevalence of deaths in females due to CNCDs in Jamaica. In 2007, 60 percent of females died from CNCDs compared to 45 percent of males and this is within the context that either 68.4 percent of females in the retirement aged cohort have CNCDs compared to $31 \%$ of males. We can forward that the disparity in prevalence rate of males and females having CNCDs account for the difference in deaths occurring to these conditions. While the prevalence of deaths among females caused by CNCDs is 57 percent in Jamaica compared to 65 percent in the world [3], there is no doubt that chronic conditions continue to erode the quality of life of females and by extension their children. This perspective is embedded in the current findings that showed that 3 in every 4 women in the working aged cohort have at least a CNCD and many of these women are in their productive and reproductive years.

Not only is there an overall feminization of chronic conditions in Jamaica like the rest of the world, particularly chronic conditions reflect a gendered phenomenon. Like in Jamaica, diabetes is a feminized phenomenon in Netherlands [38], Eastern Caribbean countries [16], and by extension the world [3]; but in this study it was discovered that more females in the working aged cohort have diabetes (30\%) compared to those in the retirement aged cohort. The issue of hypertension being a feminized disease is the same across the globe [24] as well as in Jamaica. This study adds to the literature by showing that women in the working aged cohort are more likely to have hypertension (48\%) than those in the retirement aged cohort (35\%). With the aforementioned issues along with the high probability of reporting either diabetes or hypertension in Jamaicans, irrespective of whether they are in the retirement aged or working aged cohort, we concur with the literature that these are twin problems in Jamaica as well as the wider Caribbean [39] [40]. However, where the difference emerges in this study and that of the literature is the comorbidity rate between diabetes and hypertension. According to Callender [39] fifty percent of Caribbean nationals with hypertension have diabetes and that in this study the rate is sixty-four or twenty-five percent depending on whether the people are in the retirement or the working aged cohort, respectively.

The disparities in CNCDs are not limited to gender, aged cohort and comorbidity, they extend to area of residence within the aged cohort. According to Wan et al. [24] the prevalence rate of hypertension is greater in urban than in rural dwellers except in Mexico where the reverse is case. In the present study, hypertension plays a dual role among retirement and working aged respondents. Among the working aged cohort, rural dwellers are more likely to be hypertensive and among those in the retirement aged cohort, peri-urban residents have the greatest prevalence rate of being hypertensive. With at least $50 \%$ of Jamaicans (60+ years) dwelling in rural areas and the present findings, which illustrate that 71.2 percent of diabetics and hypertensive reside in rural areas among the working aged cohort and 50.3 percent of diabetics and hypertensive dwell in rural areas among the retirement aged cohort, we are forwarding that policies must be framed in keeping with the realities in Jamaica and not be based on general information of chronic conditions in the Caribbean region, Latin America, the Americas or the rest of the world. The rationale for this is embedded in the disparities that emerge in this work compared to the literature in other parts of the globe. Baldwin et al. [41] opined that "Compared to other developing regions, LAC has the highest percentage of deaths due to NCDs and trails closely behind the group of high-income countries" and Hospedales, et al. [5] that the Caribbean region has the most deaths owing to CNCDs, these aptly capture the urgency to address CNCDs epidemic as failure to act will continue to erode quality of life, production, and productivity of peoples in region. The health disparity between the Caribbean region, world, developing nations and industrial world are due to the absence of policies, programmes and highly 
efficient public health care delivery system [26] [42], which also holds true in Jamaica.

Smith and Menah [18] opine that urbanization is among the primary reasons for CNCDs. The issue of urbanization, which according to the literature account for CNCDs, cannot be ascribed to fully explain what is occurring in Jamaica as it relates to CNCDs [18]. The rationale we forward of aforementioned perspective is levied in the disparities in CNCDs among two cohorts, with respect to area of residency. Hypertension in Jamaica among those in the working aged cohort is a rural phenomenon compared to being a peri-urban phenomenon among the retirement aged cohort. Like hypertension, the diabetes rates differ based on area of residence between the two cohorts. Urbanization can be ascribed to explain diabetes among the working aged population; but this is not so for all the cases among those in the retirement aged cohort (diabetes: retirement aged cohort, urban area, 22.3\%; working aged cohort, 33.8\%). Similar CNCDs area of residence disparity emerges for those with arthritis and other CNCDs. Such findings caution the generalized perspective of the urbanization of CNCDs for a population as evident from this study. This research concurs with the general findings of Wilks, et al.'s [15] and Bourne and Charles' [22] works that hypertension is a rural phenomenon in Jamaica, and that therefore disproves urbanization as a reason for CNCDs in all society, which is again similar to what was seen in Mexico [24]. However, urbanization can be ascribed as a cause for other CNCDs in Jamaica and this warns against wholesale labeling urbanization for cause of all CNCDs for all population and subpopulations, especially in developing countries as is noted by Unwin et al. [4]. Jamaica, which is a developing country, does not subscribe to the general observation made by Unwin et al. [4] and therefore caution should be exercised against such generalization.

The vulnerability of elderly people in Jamaica extends beyond CNCDs to the economics of their situations and how this further reduces their quality of life and life expectancy. Van et al. [7] has empirically established that there is a statistical association between poverty and chronic illness, which was concurred with by WHO [1], and Bourne who expands this to general illness and poverty [8]. Using data for Jamaica, Bourne [8] finds a direct correlation between illness rate and poverty rate, which offers an explanation of the economics of health among people, especially those in the vulnerable groups such as elderly people, poor and females. For this research, 28 percent of those in the retirement aged cohort are below the poverty line compared to 16 percent of those in the working aged cohort. The reality of elderly people is that more live in poverty due to retirement, ill-health, chronic conditions and economics of survivability becomes even more intense and burdensome for them more than those in the working age population whom experience the same set of conditions as those in the retirement aged cohort. A noticeable and stark similarity in this study is between the mortality rate and poverty rates of the two cohorts. In 2008, 1.9 times more of those in the retirement aged cohort die compared to those in the working aged cohort and another reality is that 1.8 times more of those in the retirement aged cohort are in poverty compared to those in the working aged cohort. We can deduce from the present findings that there is direct association between poverty and mortality, poverty and ill-health, poverty and chronic conditions. A previous study by Bourne et al. [43] find no direct relationship between poverty and mortality; but that an inverse statistical correlation exists between poverty and the exchange rate $(r=-0.774)$ and a direct relationship between the exchange rate and mortality $(r=0.539)$, which contradicts the present findings. Despite the aforementioned disparity, poverty is eroding the quality of life of those in the retirement aged cohort substantially more rapid pace than that for those in the working aged population.

Ferguson et al. postulate that "Anecdotal reports suggest that the interventions are either inadequate or not well promoted and that significant progress has not yet been made in reversing the trends. Data from the Jamaica Health and Lifestyle Surveys seem to support this notion" [44] this can be explained and a plausible reason is that is not forwarded. Research is critical to understanding issues and when there is no empirical basis upon which policies are formulated; authority, common sense, belief and cultured positions do not offer enough information for effective policy formulation. Simply put, adequate information is lacking on the matters of CNCDs in Jamaica, and this is a part of the problem to effectively execute a policy to address this epidemic in the society. The present findings show that wholly designing programmes for CNCDs for the elderly population would not be effective as there are health disparities between those in the working aged population, which accounts for $60 \%$ of the population in 2007, and the retirement aged cohort, which comprises of $9.6 \%$ of the population. It is the unhealthy lifestyle practices in the working aged cohort that will transcend into prevalence of CNCDs in later life as is evident from this study. Policy initiatives to address CNCDs in Jamaica, must include diseases, gender, age, socio-culturally, area of residence and research specific as these would target the root causes of the issues and not a comprehensive approach that oftentimes hits and misses the target as is evident 
from the perspective of Ferguson et al. [44]. This research creates a profile of those with CNCDs, disaggregate the issues and can be the platform for initiatives that would yield more effective results in the fight against the high prevalence of chronic conditions in Jamaica. Using national cross-sectional probability data for 2002 and 2007 on Jamaica, Bourne et al. [45] indicate that 8 per 1000 reported having CNCDs in 2002 which increased to 56 per 1000 in 2007, which describes the CNCD epidemic that is silently killing people in the $21^{\text {st }}$ century. The changing faces of CNCDs to include children in the last two decades are also noted in the United States [46] [47], which are describing an epidemic that extends beyond socio-geographical barriers. The urgency to address the matter should be a global issue, holding the specificity of the local environment within context [48] and having a broader outlook on the matter that is supported by localized empirical studies in order to understand all the tenets before public health interventions can be effectively tailored to curb the new national realities.

\section{Conclusion}

Non-communicable conditions such as diabetes and hypertension are public health concerns in Jamaica, especially among female, the aged working cohort and elderly population. The reality is, at least 50 percent of all deaths are due to CNCDs, at least 56 percent of deaths due to CNCDs are women, at least 67 percent of all deaths are women 60+ years and between 54 and 65 percent of all deaths are elderly people, which is greater than that in many low to middle income countries as well as the region of the Americas. This study highlights the erosion of the quality of life among the retired aged population due to poverty, area of residence, sedentary lifestyle, and other unhealthy behaviors including not seeking medical attention and purchasing medications when experiencing ill-health. Unfortunately, these conditions are not limited to adults but will have a significant impact on the children and adolescents. As evident in the Americas, other developed and developing nations, these health conditions are public health and economic burdens as each country struggles to control the increases in these non-communicable diseases. Overall, it is imperative that age, gender, area of residence specific and culturally relevant policies be developed in collaboration with governmental and non-governmental organizations initiatives and programmes as well as in tandem with the efforts of health professionals to effectively address these health matters, without delay.

\section{Acknowledgements}

The researchers would like to extend their gratitude to Derek Gordon Databank, University of the West Indies [distributors], for making the dataset (i.e., Jamaica Survey of Living Conditions) allow for use, for this study.

\section{References}

[1] World Health Organization (2005) Preventing Chronic Diseases a Vital Investment. WHO, Geneva.

[2] United Nations Secretary-General Ban Ki-moon (2010) Global Strategy for Women’s and Children's Health. New York.

[3] World Health Organization (2008) Global Burden of Disease 2004 Update. WHO, Geneva.

[4] Unwin, N., Setel, P., Rashid, S., Mugusi, F., Mbanya, J.C., Kitange, H., Hayes, L., Edwards, R., Aspray, T. and Alberti, K.G. (2001) Noncommunicable Diseases in Sub-Saharan Africa: Where Do They Feature in the Health Research Agenda? Bull World Health Organ, 79, 947-953.

[5] Hospedales, C.J., Samuels, T.A., Cummings, R., Gollop, G. and Greene, E. (2011) Raising the Priority of Chronic Noncommunicable Diseases in the Caribbean. Revista Panamericana de Salud Pública, 30, 393-400.

[6] Abdulkadri, A.O., Cunningham-Myrie, C. and Forrester, T. (2009) Economic Burden of Diabetes and Hypertension in CARICOM States. Study of Economy \& Society, 58, 175-197.

[7] Van Agt, H.M.E., Stronks, K. and Mackenbach, J.P. (2000) Chronic Illness and Poverty in the Netherlands. European Journal of Public Health, 10, 197-200. http://dx.doi.org/10.1093/eurpub/10.3.197

[8] Bourne, P.A. (2009) Impact of Poverty, Not Seeking Medical Care, Unemployment, Inflation, Self-Reported Illness, Health Insurance on Mortality in Jamaica. North American Journal of Medical Science, 1, 99-109.

[9] Echouffo-Tcheugui, J.B. and Kengne, A.P. (2011) Chronic Non-Communicable Diseases in Cameroon-Burden, Determinants and Current Policies. Globalization and Health, 7, 44. http://dx.doi.org/10.1186/1744-8603-7-44

[10] Mathers, C.D., Boerma, T. and Ma Fat, D. (2009) Global and Regional Causes of Death. British Medical Bulletin, 92, 7-32. http://dx.doi.org/10.1093/bmb/ldp028 
[11] Statistical Institute of Jamaica (1971-2013) Demographic Statistics, 1970-2012. Statistical Institute of Jamaica, Kingston.

[12] Pan American Health Organization/Caribbean Community (PAHO/CARICOM) (2006) Report of the Caribbean Commission on Health and Development.

[13] Mayosi, B.M., Flisher, A.J., Lalloo, U.G., Sitas, F., Tollman, S.M. and Bradshaw, D. (2009) The Burden of Noncommunicable Diseases in South Africa. Lancet, 374, 93-447. http://dx.doi.org/10.1016/S0140-6736(09)61087-4

[14] World Health Organization (2011) Global Status Report on Non-Communicable Diseases 2010. WHO, Geneva, 106.

[15] Wilks, R., Younger, N., Tulloch-Reid, M., McFarlane, S. and Francis, D. (2008) Jamaica Health and Lifestyle Survey 2007-8. Technical Report. Epidemiology Research Unit, Kingston, Tropical Medicine Research Institute, University of the West Indies, Mona.

[16] James, J., Soyibo, A.K., Hurlock, L., Gordon-Strachan, G. and Barton, E.N. (2012) Cardiovascular Risk Factors in an Eastern Caribbean Island: Prevalence of Non-Communicable Chronic Diseases and Associated Lifestyle Risk Factors for Cardiovascular Morbidity and Mortality in the British Virgin Islands. West Indian Medical Journal, 61, 429-436.

[17] Glassman, A., Gaziano, T.A., Buendia, C.P.B. and de Aguiar, F.C.G. (2010) Confronting the Chronic Disease Burden in Latin America and the Caribbean. Health Affairs, 29, 2142-2148. http://dx.doi.org/10.1377/hlthaff.2010.1038

[18] Smith, S.M. and Mensah, G.A. (2003) Population Aging and Implications for Epidemic Cardiovascular Disease in SubSaharan Africa. Ethnicity \& Disease, 13, S77-S80.

[19] Statistical Institute of Jamaica (2008) Jamaica Survey of Living Conditions, 2007 [Computer File]. Kingston, Jamaica: Statistical Institute of Jamaica [producer], 2007. Planning Institute of Jamaica and Derek Gordon Databank, University of the West Indies [distributors], Kingston.

[20] Bourne, P.A. (2012) Health of Children in Jamaica: The New Health Realities. Indian Journal of Medical Sciences, 66, 175-188. http://dx.doi.org/10.4103/0019-5359.114181

[21] Shao, R. (2014) Chronic Diseases and Health Promotion. World Health Organization, Geneva.

[22] Bourne, P.A. and Charles, C.A.D. (2011) Hypertensive and Modeling Their Social Determinants of Self-Rated Health Status in a Middle-Income Developing Nation. Journal of Clinical and Diagnostic Research, 5, 1-8.

[23] Niakara, A., Nebie, L.V., Zagre, N.M., Ouedraogo, N.A. and Megnigbeto, A.C. (2003) Knowledge of an Urban Population about Arterial Hypertension: Prospective Study Carried out in Ouagadougou, Burkina Faso. Bulletin de la Société de Pathologie Exotique, 96, 219-222.

[24] He, W., Muenchrath, M. and Kowal, P. (2012) Shades of Gray: A Cross-Country Study of Health and Well-Being of the Older Populations in SAGE Countries, 2007-2010. US Census Bureau, Washington DC.

[25] World Health Organization (2012) Good Health Adds Life to Years: Global Brief for World Health Day 2012. WHO, Geneva.

[26] Yamada, T., Chen, C.C., Chiu, I.M. and Rizvi, S.W. (2013) Non-Communicable Diseases in Developing Countries: Causes and Health Policy/Program Assessments. Journal of Tropical Diseases, 1, 117.

[27] Bourne, P.A. (2009) An Epidemiological Transition of Health Conditions, and Health Status of the Old-Old-to-Oldest-Old in Jamaica: A Comparative Analysis. North American Journal of Medical Sciences, 1, 211-219.

[28] Bogue, D.J. (1999) Essays in Human Ecology, 4. The Ecological Impact of Population Aging. Social Development Center, Chicago.

[29] Gavrilov, L.A. and Gavrilova, N.S. (2001) The Reliability Theory of Aging and Longevity. Journal of Theoretical Biology, 213, 527-545. http://dx.doi.org/10.1006/jtbi.2001.2430

[30] Gavrilov, L.A. and Gavrilova, N.S. (1991) The Biology of Life Span: A Quantitative Approach. Harwood Academic Publisher, New York.

[31] Charlesworth, B. (1994) Evolution in Age-Structured Populations. 2nd Edition, Cambridge University Press, Cambridge. http://dx.doi.org/10.1017/CBO9780511525711

[32] Medawar, P.B. (1946) Old Age and Natural Death. Modern Q., 2, 30-49.

[33] Carnes, B.A. and Olshansky, S.J. (1993) Evolutionary Perspectives on Human Senescence. Population and Development Review, 19, 793-806. http://dx.doi.org/10.2307/2938414

[34] Population Reference Bureau (2012) Today’s Research on Aging. Population Reference Bureau, 6, 1-7.

[35] Puska, P. (2011) Non-Communicable Diseases—-Neglected Diseases in Global Health Work? European Journal of Public Health, 21, 269-270. http://dx.doi.org/10.1093/eurpub/ckr052

[36] Hunter, D.J. and Reddy, K.S. (2013) Noncommunicable Diseases. New England Journal of Medicine, 369, $1336-1343$. http://dx.doi.org/10.1056/NEJMra1109345

[37] Phaswana-Mafuya, N., Peltzer, K., Chirinda, W., Musekiwa, A., Kose, Z., Hoosain, E., Davids, A. and Ramlagan, S. 
(2013) Self-Reported Prevalence of Chronic Non-Communicable Diseases and Associated Factors among Older Adults in South Africa. Global Health Action, 6, 20936.

[38] Nielen, M.M.J., van Sijl, A.M., Peters, M.J.L., Verheij, R.A., Schellevis, F.G. and Nurmohamed, M.T. (2012) Cardiovascular Disease Prevalence in Patients with Inflammatory Arthritis, Diabetes Mellitus and Osteoarthritis: A CrossSectional Study in Primary Care. BMC Musculoskeletal Disorders, 13, 150. http://dx.doi.org/10.1186/1471-2474-13-150

[39] Callender, J. (2000) Lifestyle Management in the Hypertensive Diabetic. Cajanus, 33, 67-70.

[40] Morrison, E. (2000) Diabetes and Hypertension: Twin Trouble. Cajanus, 33, 61-63.

[41] Baldwin, W., Kaneda, T., Amato, L. and Nolan, L. (2013) Noncommunicable Diseases and Youth: A Critical Window of Opportunity for Latin America and the Caribbean. The Population Reference Bureau, Washington.

[42] Burroughs Peña, M.S., Abdala, C.V.M., Silva, L.C. and Ordúñez, P. (2012) Usefulness for Surveillance of Hypertension Prevalence Studies in Latin America and the Caribbean: The Past 10 Years. Revista Panamericana de Salud Pública, 32, 15-21. http://dx.doi.org/10.1590/S1020-49892012000700003

[43] Bourne, P.A., Solan, I., Sharpe-Pryce, C., Campbell-Smith, J. and Francis, C. (2014) Human Ageing, Mortality and the Role of Macroeconomics Variables in Determining Death at Older Ages. Epidemiology, 4, 144. http://dx.doi.org/10.4172/2161-1165.1000144

[44] Ferguson, T.S., Tulloch-Reid, M.K., Cunningham-Myrie, C.A., Davidson-Sadler, T., Copeland, S., Lewis-Fuller, E. and Wilks, R.J. (2011) Chronic Disease in the Caribbean: Strategies to Respond to the Public Health Challenge in the Region. What Can We Learn from Jamaica’s Experience? West Indian Medical Journal, 60, 397-411.

[45] Bourne, P.A., McDaniel, S., Williams, M.S., Francis, C., Kerr-Campbell, M.D. and Beckford, O.W. (2010) The Changing Faces of Diabetes, Hypertension and Arthritis in a Caribbean Population. North American Journal of Medical Sciences, 2, 221-229.

[46] Orchard, T.J. (2013) The Changing Face of Young-Onset Diabetes: Type 1 Optimism Mellowed by Type 2 Concerns. Diabetes Care, 36, 3857-3859. http://dx.doi.org/10.2337/dc13-1457

[47] Narayan, K.M., Boyle, J.P., Thompson, T.J., Sorensen, S.W. and Williamson, D.F. (2003) Lifetime Risk for Diabetes Mellitus in the United States. JAMA, 290, 1884-1890. http://dx.doi.org/10.1001/jama.290.14.1884

[48] Bourne, P.A., Francis, C., Sharpe-Pryce, C., Davis, A.H. and Solan, I. (2014) Diabetes, Hypertension, Arthritis and Other Chronic Non-Communicable Diseases in an English-Speaking Caribbean Nation: A Health Perspective. Journal of Endocrinology and Diabetes, 1, 12. 